\title{
Avaliação da postura corporal de violinistas e violistas
}

\author{
Clarissa Stefani Teixeira (UFSC, Florianópolis, SC) \\ clastefani@gmail.com \\ Fausto Kothe (UFPR, Curitiba, PR) \\ fausto.viola@gmail.com \\ Érico Felden Pereira (UDESC, Florianópolis, SC) \\ ericofelden@gmail.com \\ Eugenio Andrés Díaz Merino (UFSC, Florianópolis, SC) \\ merino@deps.ufsc.br
}

\begin{abstract}
Resumo: Para a prática instrumental há necessidade de acessórios, como a partitura e estante. Assim como em computadores, o trabalho dos músicos necessita ajustes para que posturas desnecessárias não sejam adotadas ao longo da jornada das atividades, causando fadiga ou problemas futuros. 0 objetivo deste estudo foi avaliar a distância visual, o ângulo visual, a altura da partitura musical e o ângulo cervical de 11 músicos de cordas (violino e viola). Os resultados apresentaram associação entre o ângulo visual e a distância e a altura da partitura, assim como a distância visual com a altura da partitura. Os resultados foram de $100,23 \pm 5,46 \mathrm{~cm}$ para a altura da partitura, $89,36 \pm 8,22 \mathrm{~cm}$ para a distância visual, 9,23 $\pm 0,79^{\circ}$ para o ângulo visual e $49,86 \pm 5,71^{\circ}$ para o ângulo da cervical. Apenas o ângulo da cervical estava fora dos padrões recomendados (indicação máxima de $30^{\circ}$ ) e deve ser analisado com maior profundidade em estudos futuros. Conforme o ritmo, novas obras, troca de acessórios e/ou instrumento, estas dimensões poderão ser modificadas, mas sem interferir nas condições visuais, físicas e de conforto. As dimensões estiveram dentro dos limites recomendados pela ergonomia.
\end{abstract}

Palavras-chave: ergonomia; situação de trabalho; músicos.

\section{Body postural evaluation of violinists and violists}

Abstract: For the instrumental practice there are accessories needs, as the musical score and shelf. As well as in computers, the musicians' work needs fittings so that unnecessary postures are not adopted along the day of the activities, causing fatigue or future problems. The objective this study was to evaluate the visual distance, the visual angle, the height of the musical scores and cervical angle in 11 string musicians (violin and viola). The results presented association between the visual angle and the distance and the height of the musical score, as well as the visual distance with the height of the musical score. The results went of $100.23 \pm 5.46 \mathrm{~cm}$ to the height of the musical score, $89.36 \pm 8.22 \mathrm{~cm}$ for the visual distance, $9.23 \pm 0.79^{\circ}$ for the visual angle and $49.86 \pm 5.71^{\circ}$ for the cervical angle. Only the cervical angle was out of the recommended patterns (maximum indication $30^{\circ}$ ) and should be analyzed in greater depth in future studies. According to the rhythm, new works, accessory and/or instrument changes, these dimensions can be modified, but without interfere in the visual conditions, physics and comfort. The dimensions are inside of the limits recommended by ergonomics.

Keywords: ergonomic; work situation; musicians. 


\section{1 - Introdução}

Para a execução da obra musical as atividades desenvolvidas exigem esforços individuais que culminam com as práticas coletivas, com toda a orquestra. Como a prática das atividades desenvolvidas pelos músicos está centrada no controle motor fino manual, com atuação principalmente do córtex motor (WATSON, 2006) e há envolvimento dos canais auditivos, visuais e cinestésicos exigindo um controle de precisão, velocidade, agilidade, força e intensidade, é de fundamental importância a dedicação destinada às atividades práticas com o instrumento.

Alguns autores (PHILIPSON et al. 1990; BERQUE e GRAY, 2002; FJELLMAN-WIKLUND, BRULIN e SUNDELIN, 2003; STEINMETZ, SEIDEL e NIEMIER, 2008) identificaram os problemas relacionados com a prática instrumental e salientam a necessidade de investigações voltadas para a cinemática dos movimentos, para os ajustes nos acessórios, como a queixeira e a espaleira, para o controle da força e pressão durante a realização dos movimentos e para a dosagem das práticas que se constituem, principalmente, de movimentos repetitivos. Mesmo com indicações de avaliação e contribuição da ergonomia (BRANDFONBRENER, 2003; COSTA e ABRAHÃO, 2004; FJELLMAN-WIKLUND, BRULIN e SUNDELIN, 2003; COSTA, 2005), enquanto foco de estudo, faltam ainda investigações que centralizem a importância a adequação das situações de trabalho nos músicos de orquestra, pois para a prática instrumental há necessidade de utilização de alguns acessórios, como, por exemplo, a partitura e a estante.

No trabalho com computadores, por exemplo, normalmente são realizadas intervenções ergonômicas, e os benefícios encontrados com estas aplicações são relacionados à diminuição da carga de trabalho e aumento da produtividade (BERKHOUT, HENDRIKSSON-LARSÉN e BONGERS, 2004). Logo, a exemplo dessa situação, há necessidade de ajustes nas posturas corporais adotadas frente às atividades realizadas ao longo da jornada de trabalho.

Especificamente no trabalho dos músicos, o posicionamento adotado para a interação com 0 instrumento vem sendo descrito por alguns autores (COSTA e ABRAHÃO, 2004; COSTA, 2005). Neste sentido, observam-se preocupações como, por exemplo, as dimensões adotadas durante a prática instrumental, como ângulos e distâncias, sendo estas investigações ainda necessárias. Diante destas premissas, este estudo buscou avaliar a distância visual, o ângulo visual, a altura da partitura musical e o ângulo cervical de músicos de cordas (violino e viola), a fim de otimizar as atividades realizadas, principalmente, durante a postura sentada, que é predominante nesta atividade.

\section{2 - Metodologia}

Para a compreensão das atividades de trabalho dos músicos (a chamada prática instrumental) e, principalmente, para a compreensão das situações de trabalho foi realizada observação das atividades. Estas observações permitiram a verificação da necessidade de explicações relacionadas à postura sentada durante as atividades dos músicos.

As investigações foram realizadas em uma orquestra da região Sul do Brasil que conta com 16 músicos de violino e viola. Destes, 11 músicos, com idade de 24,27 \pm 10,09 anos, aceitaram em participar do estudo. Os instrumentistas realizam atividades de 2,27 $\pm 2,15$ horas por dia, junto ao instrumento, durante $5,27 \pm 1,27$ dias na semana. Além disso, eram realizados estudos semanais coletivos (de naipe e ensaios com a orquestra) que totalizavam $3,64 \pm 0,92$ horas.

Para a realização deste estudo foram avaliadas a altura da partitura, a distância visual, e o ângulo visual, conforme os critérios listados a seguir e ilustrados no Ex.1:

1) altura da partitura: medida entre o centro da partitura e o solo;

2) distância visual: medida da parte superior da partitura até os olhos;

3) ângulo visual: medido a partir da horizontal do nível dos olhos até a borda superior da partitura musical e medido a partir da horizontal do nível dos olhos até a borda inferior da partitura.

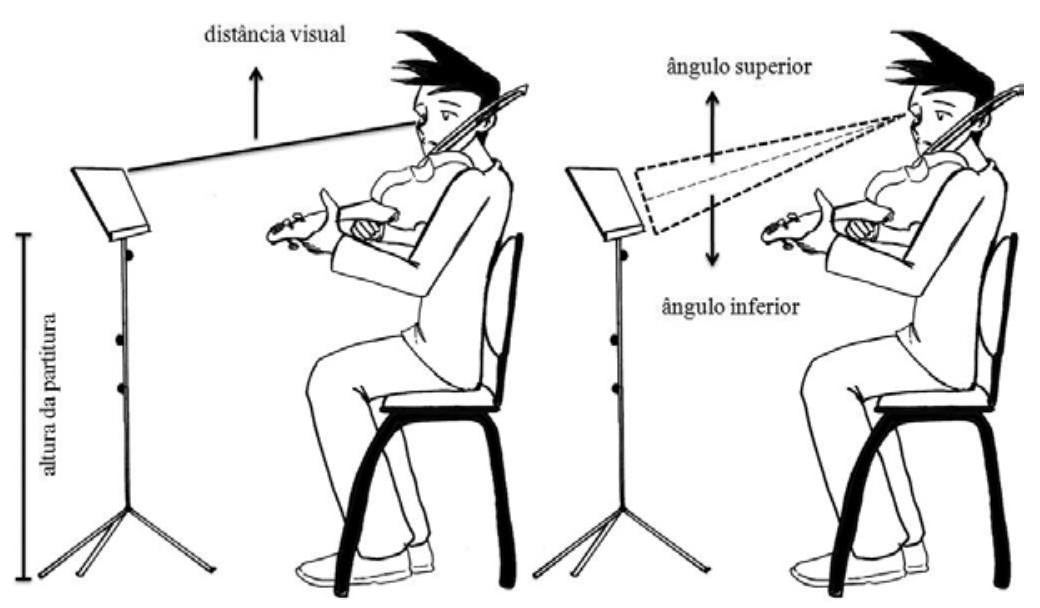

Ex.1 - Altura, distância visual e ângulo visual relacionados à estante e partitura musical. 
Além disso, foi avaliado o ângulo articular da coluna cervical. 0 ângulo da cervical foi formado a partir dos pontos anatômicos da articulação têmporomandibular (ATM), sétima vértebra cervical (C7) com a vertical, sendo a ATM o vértice do ângulo (Ex.2). Assim como no estudo de CASTRO e LOPES (2003), para a marcação dos pontos analisados, foram utilizados dois marcadores corporais esféricos e auto-adesivos, de $2,5 \mathrm{~cm}$ de diâmetro, o que facilita a identificação dos pontos para a aquisição do ângulo avaliado.

Para todas as avaliações foi utilizada uma câmera de vídeo (JVC GR-D370U, Japan) no modo automático com captura de imagem de 60 quadros por segundo, posicionada a dois metros e perpendicularmente ao plano sagital esquerdo dos músicos, a fim de obter as medidas de altura, distância visual, ângulo visual e ângulo da cervical.

A partir das filmagens, foram obtidas fotografias para a realização dos cálculos, por meio do programa adobe after effects. Para as medidas foi utilizado o Software para Análise Postural (SAPO) desenvolvido por DUARTE et al. (2006). Além disso, para a calibração do sistema quatro marcadores fixados na parede foram utilizados como referência horizontal, e um fio de prumo na vertical submetido à gravidade.

A análise das fotos obedeceu à seguinte sequência: abertura da foto, zoom de $200 \%$, calibração da imagem e marcação dos pontos de interesse, conforme procedimentos de $\mathrm{Yl}$ et al. (2008).

A postura sentada foi padronizada para a avaliação da prática musical por ser esta predominante durante os ensaios e as apresentações com a orquestra. Como no local de trabalho (ensaios com a orquestra) não havia cadeiras reguláveis, para a coleta de dados foi utilizada uma das cadeiras do próprio local.
Todos os músicos executaram uma escala maior (dó para violas e sol para violinos) onde a semínima tinha 60 batimentos por minuto, controlada por metrônomo. Este movimento foi padronizado, e escolhido, por seu desenvolvimento exigir a utilização de todo o arco e todas as cordas do instrumento.

Como os músicos estavam no ensaio da orquestra, as coletas foram realizadas entre uma e duas horas do início das práticas com o naipe, ou seja, com os ensaios destinados ao mesmo tipo de instrumento. Salienta-se que para orquestras semi-profissionais o tempo de prática diária varia entre uma e duas horas, o que permitiu a coleta de dados neste tempo visando descartar influências relacionadas ao descondicionamento e/ou fadiga pela permanência na posição (TEIXEIRA et al., 2009).

Para a coleta de dados foi solicitado que todos os equipamentos estivessem como na forma comumente utilizada durante as práticas diárias e apresentações. Assim, cada instrumentista organizou seus equipamentos para a prática instrumental. As análises não foram tomadas durante as apresentações em função da impossibilidade destas ocorrências, sendo realizadas em situação de simulação, durante a realização de uma repetição da escala após a leitura da mesma.

A análise dos dados foi realizada por meio da média e desvio padrão das medidas encontradas, ou seja, inicialmente se realizou uma média intra-sujeito (considerando as imagens de cada músico) e depois uma análise inter-sujeito, considerando valores de tendência central e dispersão. Foi realizada uma análise de correlação de Pearson para verificar associação entre todas as variáveis coletadas (distância visual, ângulo visual, altura da partitura e ângulo da cervical). Para a verificação das associações foi utilizado 0 critério adotado por MALINA (1996) que descreve correlação baixa para um valor menor que 0,30 , moderada para valor entre 0,30 e 0,60 e alta para valor superior a 0,60.

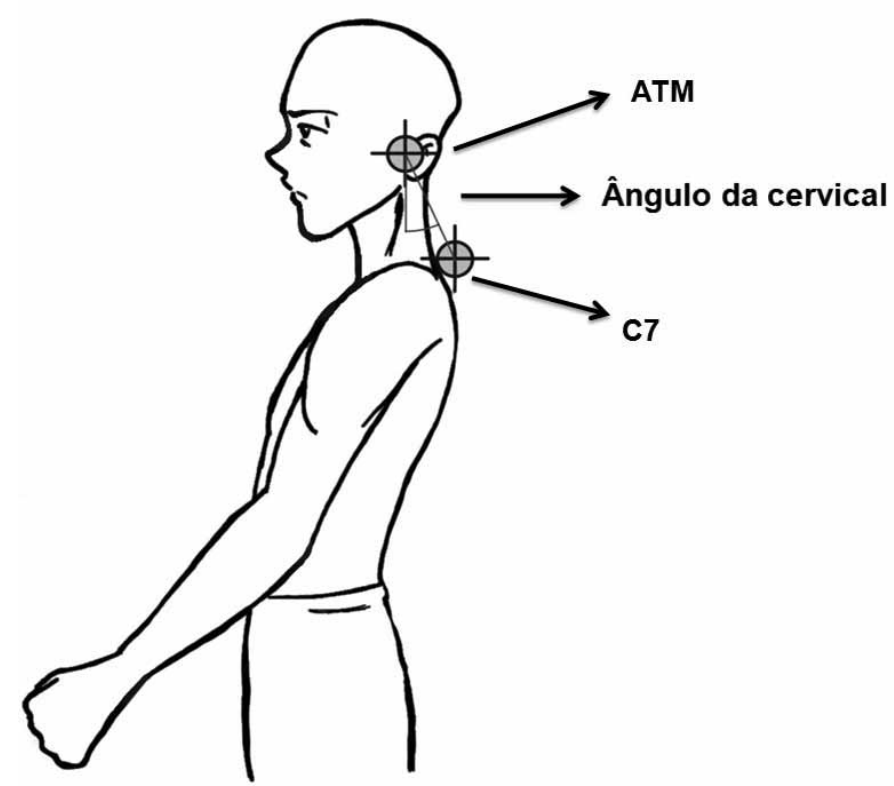

Ex.2 - Ângulo da cervical formado com a vertical. 


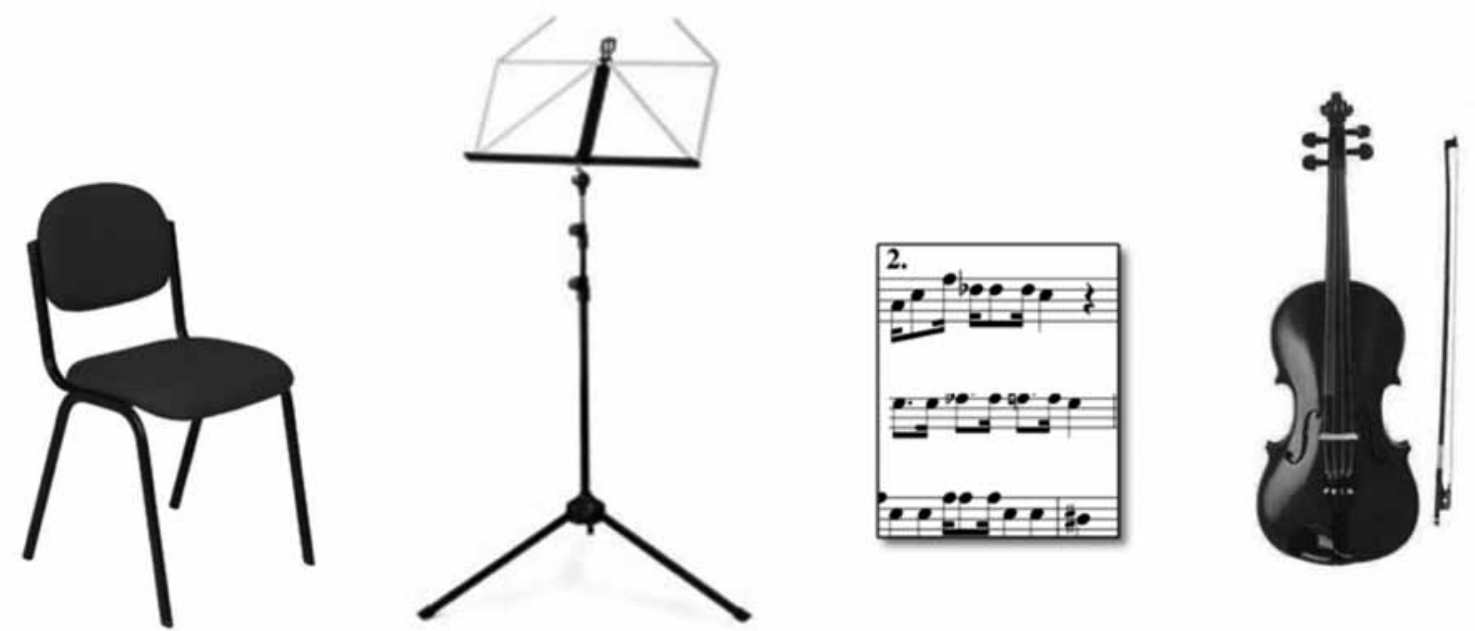

Ex.3 - Materiais de trabalho dos instrumentistas avaliados.

\section{3 - Resultados e discussão}

\section{1 - A situação de trabalho dos músicos de corda} Considera-se que o posto de trabalho do músico é constituido, geralmente, de cadeira ou banco, de estante para partituras e de suporte para o instrumento, situados em um espaço de trabalho que em geral é uma sala de estudos ou o próprio palco. A ausência de regulagens nestes itens básicos contribui significativamente para que o posto de trabalho do instrumentista não seja equipado de forma adequada, acarretando esforços extras para manutenção de postura por estes músicos, e gerando desgastes físicos que podem dificultar a atividade em si (COSTA, 2005).

A situação de trabalho dos instrumentistas avaliados é constituída basicamente por cadeira (que não possui regulagem), estante (com regulagem), partitura musical e o próprio instrumento musical (com seus respectivos acessórios - queixeira, espaleira) e pode ser identificado no Ex.3 acima.

Conforme observações, uma das fragilidades do trabalho dos músicos está relacionada à postura sentada, o que leva a necessidade de maiores esclarecimentos da correta utilização do corpo para as práticas instrumentais.

Além disso, no palco durante as apresentações a estante e a partitura são usadas por mais de um músico, e o espaço existente para seu posicionamento pode variar, com interferência sobre os outros aspectos analisados. Mesmo assim, as observações permitem identificação de um posicionamento voltado tanto a partitura quanto ao maestro. Porém, este estudo limitou-se a uma análise feita por meio de simulação não sendo possivel a coleta de dados durante as apresentações dos músicos. Assim, a divisão do posto de trabalho, mais especificamente a estante, não foi levada em consideração, sendo a coleta associada apenas às práticas individuais com o instrumento.

\section{2 - As atividades musicais e a postura sentada}

Estudos sobre a posição sentada evidenciam que há um tipo de assento para cada função ou atividade, a depender de suas exigências e das características do indivíduo. Notadamente, o mito da postura correta se desfaz na medida em que o ser humano não mantém uma mesma postura por muito tempo dada as necessidades de irrigação sanguínea, de condução de oxigênio e de nutrientes aos músculos. As posturas assumidas resultam, portanto, de uma solução de compromisso entre as exigências da tarefa, o mobiliário disponível e o estado de saúde do sujeito. Desta maneira, um posto de trabalho adequado é aquele que permite variações posturais, facilitando a diminuição de contrações musculares contínuas presentes na manutenção de uma mesma postura, o chamado trabalho estático (GRANDJEAN, 1998; COSTA, 2005).

As atividades realizadas pelos instrumentistas de violino e viola em orquestras são predominantemente sentadas. Mesmo assim, na literatura consultada não foram encontrados estudos que visem comparar diferentes cadeiras para a prática destes profissionais. Apenas o estudo de KÖENIG (2007) apresenta a chamada Kneeling chair que é aquela com o acento inclinado favorecendo a lordose lombar. NORRIS (1995) também indica esta cadeira e menciona que o uso da mesma permite que o centro de gravidade fique diretamente sobre os isquios. 0 autor ainda complementa que sentado com os quadris e joelhos em $90^{\circ}$ há uma tendência de se causar inversão da curvatura lombar, prejudicando também a respiração.

Como as atividades com a orquestra, na maioria do tempo, não são realizadas nos locais de trabalho e as apresentações são realizadas em locais diferenciados, não há indicação de substituição para cadeiras reguláveis para o grupo estudado. Além disso, esses mesmos indivíduos 
permanecem em uma mesma posição em tempos relativamente menores comparando com outras profissões. A importância de se entender como fazer uso da correta postura, durante as práticas instrumentais, está relacionada ao fato da permanência nesta posição, principalmente nos ensaios individuais, que são desenvolvidos pela maioria dos músicos em suas próprias casas.

Para qualquer local onde forem desenvolvidos os estudos com o instrumento musical, há necessidade de seguir as corretas dimensões para que a postura sentada não seja considerada como um potencial de riscos para o trabalho. Além disso, é necessário que cada instrumentista saiba e consiga ajustar corretamente os acessórios para a atividade do trabalho. Pode-se dizer que melhorando a postura sentada, os benefícios serão identificados na coluna lombar, torácica e cervical podendo facilitar 0 desenvolvimento dos movimentos dos membros superiores.

Para as cadeiras disponíveis no local de trabalho, a altura poplitea deve ser identificada, de forma que a coxa fique na horizontal formando com o joelho uma angulação de aproximadamente $90^{\circ}$. É importante observar que a angulação formada entre o tronco e a coxa deve estar entre $90^{\circ}$ e $120^{\circ}$ (IIDA, 2005). Nota-se também que os pés precisam estar apoiados no solo e o tronco com as curvaturas naturais preservadas.

Além disso, algumas alternativas poderiam ser adotadas para a melhoria das condições da postura sentada. Primeiramente, a postura em que o apoio corporal é suportado pelos ísquios (região óssea que constitui o osso pélvico), ainda deve ser mantida, principalmente pelos instrumentistas que não utilizam o encosto da cadeira. Se não houver suporte pelos ísquios as posturas podem ser prejudiciais. Como consequência, influências negativas podem ocorrer tanto nas outras partes do corpo, quanto na própria coluna, gerando os sintomas musculoesqueléticos. Para que a postura seja corrigida os isquios devem estar posteriorizados e a crista iliaca (região óssea que constitui o ílio que por sua vez constitui a pelve) anteriorizada (de forma a realizar uma anteversão pélvica), ultrapassando a posição dos ísquios que devem estar no sentido vertical.

Estas indicações já foram observadas em outros estudos com músicos de orquestras enfocando principalmente os diferentes posicionamentos de tronco assim como indicam CALLAGHAN e DUNK (2002) e O'SULLIVAN et al. (2006). Os mesmos autores classificaram a posição sentada conforme as curvaturas da coluna em: 1) postura lombo-pélvica sentada ereta, definida como a postura na qual a pelve, a lordose lombar e a cifose torácica estão em posição neutra; 2) em postura sentada em relaxamento, caracterizada pela retroversão da pelve, o que reduz a lordose lombar; e 3) em postura torácica ereta, com a anteversão da pelve, que gera um aumento da curvatura lombar, assim como ilustra o Ex.4.

Os problemas de postura em períodos prolongados de tempo fazem com que haja compressão dos capilares, que tendem a se fechar, prejudicando o retorno venoso e, com o tempo, podendo ainda necrosar (HUET e MORAES, 2003). Para KAYIS e HOANG (1999); KINGMA e VAN DIEËN (2008) posturas estáticas por períodos prolongados estão associadas a desordens musculoesqueléticas. Quando há constrangimento postural sem possibilidade de variação da posição os acometimentos são identificados entre 10 e 15 minutos. Primeiramente, há sensação de queimação sobre os ísquios, depois sobre os trocânteres, e quando os tecidos moles (como músculos e pele) se afastam a área de pressão aumenta e os sintomas se agravam, tendo sensação de dor em aproximadamente 30 minutos (HUET e MORAES, 2003). HAYNES e WILLIAMS (2008) salientam que as dores, muitas vezes, são relacionadas à posição sentada por longos períodos de tempo.

Os cuidados com o tronco não estão apenas relacionados à posição dos ísquios e pressão causada sobre estes. 0 tronco deve estar de tal forma que não esteja nem muito inclinado para frente, onde segundo KAYIS e HOANG (1999) há maiores compressões do disco lombar, nem com posturas muito relaxadas, pois acaba desestabilizando o restante dos segmentos corporais.

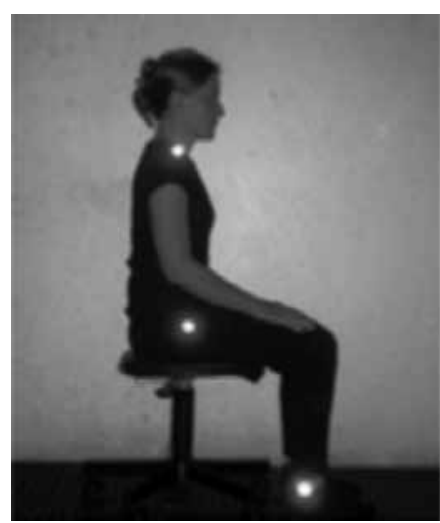

posição neutra

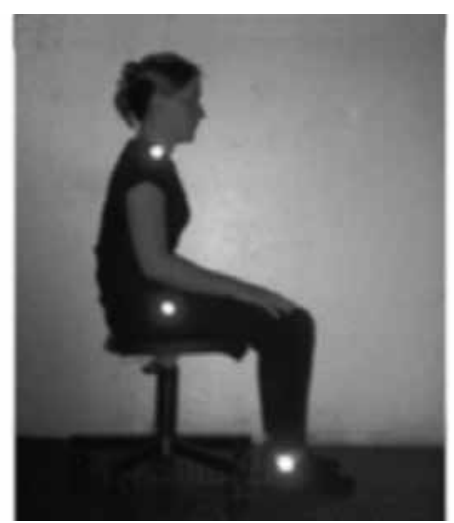

retroversão da pelve

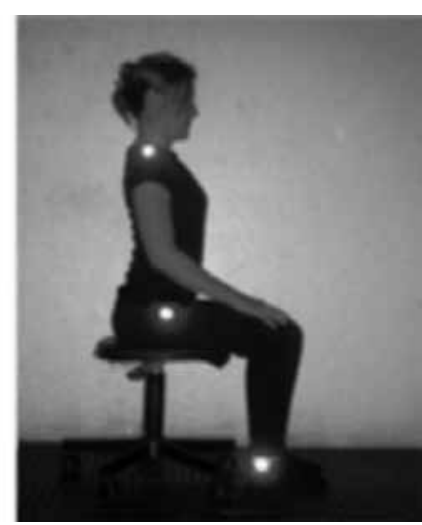

anteversão da pelve

Ex.4 - Postura sentada.

Fonte: MARQUES, HALLAL e GONÇALVES (2010, p.272). 
Para a manutenção da postura adequada uma contração abdominal também é necessária. SALVE e BANCOFF (2004) chamam a atenção para a fraqueza e encurtamento muscular nas regiões do pescoço, região das costas, cintura escapular e abdominal. Os autores relacionam a fraqueza dos músculos da parte superior das costas com a cifose, assim como o encurtamento da região do peitoral. Já a fraqueza dos músculos abdominais causa inclinações na pelve para frente e a lordose lombar. 0 iliopsoas ${ }^{1}$ (responsável em uma ação primária por realizar a flexão do quadril e em uma ação secundária por realizar a rotação externa do fêmur) encurtado também leva a uma lordose acentuada da lombar, bem como uma inclinação pélvica.

Os mesmos autores ainda indicam que inclinações e rotações do tronco devem ser evitadas, assim como apoios assimétricos. $\mathrm{Na}$ prática instrumental estas considerações não são diferentes. Porém, dependendo da posição do músico em relação à orquestra, a posição poderá ser diferenciada com intuito de atender as necessidades momentâneas. Isto se deve a necessidade de visualização, durante as práticas, da partitura, do maestro, do spalla, e do chefe de naipe. Conforme o posicionamento de cada músico no palco, não há como os instrumentistas manterem uma posição de forma frontal para o público e para o maestro, por isso, durante as apresentações e ensaios coletivos, pequenas rotações e inclinações poderão ocorrer. Porém, há uma tendência de ajustamentos de forma que corpo esteja voltado principalmente à partitura e ao maestro.

Do ponto de vista da atividade muscular, pode-se considerar a posição sentada como de baixo risco para algias da coluna, entretanto, as estruturas articulares, tornam-se expostas a maiores riscos de lesão. No estudo de BRITO et al. (2003) foram encontradas maiores incidências de dores nos indivíduos que realizavam trabalhos em postura em pé sem carga e de maneira estática $(55,56 \%)$. Nos trabalhadores que se utilizavam da postura sentada, como no caso dos músicos de violino e viola, as dores na coluna, foram relatadas por 53,49\%. De maneira geral, foi identificado que aqueles que realizavam um trabalho sentado apresentaram predominantemente queixas de dores principalmente na região cervical, quando comparadas à coluna torácica, lombar e sacral.

Alguns aspectos devem ser considerados, como a figura do professor como conscientizador. A auto-observação também pode ser utilizada como estratégia corretiva. FONSECA (2005) comenta que a auto-observação deve ser acompanhada por espelho ou por filmagens para posterior análise.

Diante destas indicações, há necessidade de investigações relacionadas à interferência da postura sobre os ângulos visual e cervical, bem como a altura e distância visual.

\section{3 - As atividades instrumentais e a utilização da estante e partitura musical}

As medidas observadas para as variáveis relacionadas à estante e partitura musical (altura, distância e ângulo visual) estão ilustradas no Ex.5.

Assim como a cadeira, o posicionamento da estante também deve estar com as posições adequadas, para que o tronco e, principalmente a cervical, não seja influenciada por estas posições. Como pode ser observado no Ex.5 abaixo, as maiores atenções devem estar focadas na distância visual que a partitura se encontra. Porém, todas as mensurações feitas se encontram na faixa das medidas recomendadas por IIDA (2005) e, no caso do ângulo de visão, o mesmo encontra-se no nível de conforto para as atividades desenvolvidas no trabalho.

Uma das problemáticas relatadas por alguns estudos é relacionada com as condições das partituras musicais e estas, se não conservadas, podem ser agravadas conforme as medidas visuais. COSTA (2003) relata que a partitura musical, enquanto artefato mediador do trabalho do músico constitui a prescrição do som a ser obtido, em nuanças explicitadas por caracteres e códigos específicos. Caso a partitura esteja em condições desfavoráveis à leitura realizada à primeira vista, seja por estar ilegivel, ser manuscrita, fazer uso de caracteres pouco usuais, de tamanho inadequado

\begin{tabular}{|c|c|c|l|}
\hline Variáveis & \multicolumn{1}{|c|}{$\begin{array}{c}\text { Medidas } \\
\text { recomendadas }\end{array}$} & $\begin{array}{c}\text { Medidas encontradas } \\
\text { (média } \pm \text { desvio padrão) }\end{array}$ & \multicolumn{1}{|c|}{ Observações } \\
\hline \multicolumn{2}{|c|}{ Estante e partitura musical } \\
\hline Altura & $90-115 \mathrm{~cm}$ & $100,23 \pm 5,46 \mathrm{~cm}$ & $\begin{array}{l}\text { A altura deve ser medida entre o centro da } \\
\text { partitura e o piso. }\end{array}$ \\
\hline \multirow{2}{*}{ Distância visual } & $41-93 \mathrm{~cm}$ & $89,36 \pm 8,22 \mathrm{~cm}$ & $\begin{array}{l}\text { A distância visual deve ser medida da parte } \\
\text { superior da partitura até os olhos. }\end{array}$ \\
\hline \multirow{2}{*}{ Ângulo visual } & \multirow{2}{*}{$0-30^{\circ}$} & $21,28 \pm 1,85^{\circ}$ & $\begin{array}{l}\text { Ângulo visual medido a partir da horizontal do } \\
\text { nivel dos olhos até a borda superior da partitura. }\end{array}$ \\
\cline { 2 - 4 } & & $9,23 \pm 0,79^{\circ}$ & $\begin{array}{l}\text { Ângulo visual medido a partir da horizontal do } \\
\text { nivel dos olhos até a borda inferior da partitura. }\end{array}$ \\
\hline
\end{tabular}

Ex.5 - Medidas recomendadas e observadas para as variáveis relacionadas a estante e a partitura musical. 
ou apresentar marcações anteriores ambíguas ou distintas das intenções interpretativas do maestro, a atenção será redobrada para evitar erros na execução.

A importância em se ter uma situação de trabalho em conformidade com as adequações do usuário, está no fato de que além do aumento do conforto, diminuição da carga e aumento da produtividade, há também possibilidade de se realizar um trabalho contínuo, ou seja, mais horas frente à máquina (BERKHOUT, HENDRIKSSON-LARSÉN e BONGERS, 2004). No caso dos músicos, estas indicações são fundamentais, uma vez que, há relatos de práticas contínuas e muitas vezes sem pausas.

DIMATOS (2007) indica ainda que ensaios longos e prática intensa de movimentos repetitivos, sem intervalos, são, certamente, fatores relevantes para o aparecimento de doenças profissionais. Desta forma, alguns autores vêm considerando que as modificações pertinentes para as atividades de trabalho incluem intervalos para o descanso. Considerando especificamente os ensaios, pode-se dizer que as indicações são para cinco minutos em cada 30 ou 45 minutos de prática (DIMATOS, 2007). BROOKS (1993) e BOISSÉ-RHEAULT e BOUTHILLIER (2000) indicam que nestes períodos de intervalos é que a pressão do túnel do carpo, por exemplo, retorna ao normal.

Neste mesmo contexto, DIMATOS (2007) informa que se frequentes e regulares durante as sessões de prática, os intervalos podem aliviar a distensão dos grupos de músculos que carregam o peso, bem como as ações repetitivas de pequenos grupos de músculos. MANDALOZZO e COSTA (2007) indicam que os descansos destinados aos trabalhadores constituem medidas de ergonomia, pois possibilitam o descanso para a recuperação física e mental. Para WU (2007) a falta de repouso é considerada um dos condicionantes para as queixas musculoesqueléticas especialmente em instrumentistas de orquestra.

Segundo verbalizações dos músicos, as pausas são realizadas apenas durante o ensaio coletivo, com uma parada de 15 minutos, e durante as atividades individuais não há pausas sistemáticas, o que consequentemente agrava todos os resultados encontrados.

Embora a regra geral dos intervalos das atividades de trabalho esteja fixada no Artigo 71 da Consolidação das Leis do Trabalho (CLT) as atividades desenvolvidas pelos instrumentistas devem ser encaradas de forma diferenciada, assim como indica MANDALOZZO e COSTA (2007) tendo como base a própria atividade desempenhada o que permite levar em consideração as situações onde a atividade é mais desgastante. Como exemplo, os autores citam as atividades desenvolvidas com os serviços permanentes de mecanografia. Para tal atividade a cada 90 minutos de trabalho são concedidos 10 minutos de intervalo, sendo computados como tempo de labor - Artigo 72 da CLT. Os autores explicam que para os digitadores, por força da Súmula 342 do Tribunal Superior do Trabalho a Norma Regulamentadora 17 (NR17) que trata da Ergonomia prevê o mesmo intervalo (10 minutos) a cada 50 minutos trabalhados.

Observa-se que tais indicações parecem contraditórias. MANDALOZZO e COSTA (2007) indicam que na prática a primeira norma (Artigo 71 da CLT) deve ser aplicada, pois a competência de legislar sobre o Direito do Trabalho é da União (segundo artigo 22, I, da Constituição Federal) tendo em vista que as Normas Regulamentadoras apresentam outra origem. No entanto, segundo os mesmos autores, outra interpretação é viável se realizada no sentido de aplicação do principio mais favorável ao trabalhador, fazendo uso assim das indicações das normas regulamentadoras.

Como 0 trabalho dos instrumentistas apresenta características de digitação de notas se pode aproximar as associações no que tange a necessidade de intervalos. Embora as recomendações encontradas na literatura para o contexto musical variem tanto para a duração quanto para a frequência (DIMATOS, 2007), pode-se dizer que a cada 50 minutos de atividade um intervalo de pelo menos 10 minutos de repouso deveria ser realizado.

NORRIS (1995) indica que nos intervalos de trabalho algumas estratégias são importantes para a recuperação do sistema osteo-mio-articular e a prevenção de desordens. Para o autor, a cada meia hora de trabalho devem ser feitos intervalos de dois a três minutos e, ao completar uma hora de trabalho, devem ser feitos intervalos de cinco a dez minutos.

DIMATOS (2007) coloca ainda que a questão do intervalo é importante não apenas para o descanso físico-mental em si, mas também em função do aprendizado que é conseguido após uma série de pequenos periodos de descanso entre as sessões. Desta forma, identifica-se que as preocupações da estrutura organizacional se associam segundo ABRAHÃO (2000) à tentativa de desvendar as lógicas de funcionamento e suas consequências, tanto para a qualidade de vida no trabalho, quanto para o desempenho da produção. Assim, as melhorias para a otimização dos treinamentos (estudos) com 0 instrumentos que impulsionam a performance devem ser consideradas com vistas para os intervalos.

Especificamente para o trabalho dos músicos, a Lei $n^{\circ}$ 3.857 - de 22 de dezembro de 1960 que cria a Ordem dos Músicos do Brasil e dispõe sobre a regulamentação do exercício da profissão de músico prevê apenas, no Art. $42 \S 2^{\circ}$, intervalo obrigatório de repouso de no mínimo 30 minutos para os casos de período normal de trabalho. No Art. 46 é previsto que a cada seis dias consecutivos de trabalho, corresponderá a um dia de descanso obrigatório remunerado, que constará do quadro de horário afixado pelo empregador; e no Art. 47 consta que a cada período diário de trabalho, haverá um intervalo de 11 (horas), no mínimo, destinado ao repouso (OMB, 2009). 
Estas considerações demonstram fragilidades para a organização e regulamentação da profissão com vistas no controle de problemas de saúde e dos quadros de doenças e afastamentos do trabalho.

Somado a esses achados, salienta-se a importância de estudos com foco na atuação dos instrumentistas e suas interações com os elementos que constituem os postos de trabalho, como por exemplo, os estudos associados ao posicionamento das estantes que normalmente durante as apresentações são posicionadas de modo diferenciado ao encontrado pelo presente estudo e ainda de forma mais baixa, uma vez que, há necessidade que o público visualize o músico sem que este esteja coberto pela partitura.

As correlações encontradas estão ilustradas no Ex.6, e conforme os critérios de MALINA (1996) as associações podem ser consideradas altas.

As associações encontradas demonstram a influência entre as diferentes medidas. 0 ângulo visual se correlacionou de forma negativa com a distância visual e com a partitura, ou seja, há uma associação inversa entre essas medidas conforme modificações de altura e distância para o ângulo visual, ou vice-versa. Já a distância visual e a altura da partitura se correlacionaram $(r=0,76 ; p=0,029)$ de forma positiva, ou seja, quanto maior a distância visual, maior será a tendência em se ter uma maior altura para a partitura. Em outras palavras pode-se dizer que quanto mais longe 0 instrumentista estiver posicionado da estante maior

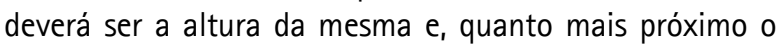
instrumentista estiver da estante, mais baixa a mesma poderá ficar posicionada para se conseguir uma boa visualização. No entanto, estes posicionamentos podem interferir no posicionamento corporal como um todo e em especial na região da coluna cervical.

\section{4 - As atividades instrumentais e o posicionamento da coluna cervical}

Especificamente nos instrumentos violino e viola, a cabeça tem papel importante para a manutenção da posição do instrumento, liberando os dedos da mão esquerda para pressionar as cordas com precisão e velocidade, para 0 tocar (BLUM e RITTER, 1990; PETRUS e ECHTERNACHT, 2004). Dada importância desta região, para a prática instrumental, a cervical é citada como uma das regiões mais acometidas pelas queixas musculoesqueléticas dos músicos (GLATZ, POFFO e PRZSIEZNY, 2006; STEINMETZ, SEIDEL e NIEMIER, 2008).
Em muitos casos, estas queixas estão associadas às angulações encontradas durante a realização de atividades do trabalho (STRAKER, JONES e MILLER, 1997, IIDA, 2005; STEINMETZ, SEIDEL e NIEMIER, 2008). Segundo IIDA (2005) e GLATZ, POFFO e PRZSIEZNY (2006) a flexão da cabeça numa amplitude maior que $30^{\circ}$ exige tensão dos músculos da coluna, levando a ocorrência de dores e desconfortos nos ombros e coluna cervical. Para CHAFFIN (1973) o aumento na angulação da cervical faz com que haja fadiga precoce na musculatura do pescoço. Similarmente STRAKER et al. (1992) indicaram que há desconforto com o aumento do ângulo cervical (de $0^{\circ}$ para $45^{\circ}$ ).

De maneira geral, há uma tendência em sentir dores com aumento da flexão da cervical (STRAKER, JONES e MILLER, 1997). Para ARIENS et al. (2001) o risco de dor na região do pescoço aumenta com a flexão da cabeça quando se trabalha com angulações maiores que $20^{\circ}$ por mais de $70 \%$ do tempo de trabalho. Estas indicações se relacionam com as queixas de dor e desconforto relatadas por muitos instrumentistas, uma vez que, durante todo o tempo de trabalho angulações maiores que $30^{\circ}$ são mantidas.

Para STRAKER, JONES e MILLER (1997) as indicações de dor/ desconforto estão relacionadas à manutenção de posturas com ângulos da cervical entre $57,4 \pm 2,9^{\circ}$ e 50,8 $\pm 2,9^{\circ}$ por mais de 20 minutos. De forma geral, os valores angulares de flexão cervical foram acima das recomendadas para a prática do trabalho. Além disso, durante a jornada de trabalho dos instrumentistas a posição de flexão da cervical pode ser considerada como prejudicial, uma vez que, o tempo de trabalho diário foi de 2,27 $\pm 2,15$ horas por dia durante $5,27 \pm 1,27$ dias na semana.

No trabalho de outras profissões, como a dos dentistas, AKESSON et al. (1997) encontraram valores angulares de $39^{\circ}$, já em trabalhadores manuais de pele e couro HANSSON e MIKKELSEN (1997) encontraram ângulos de $40^{\circ}$. De acordo com estes estudos, pôde-se observar valores angulares maiores no trabalho desenvolvido pelos músicos, o que somado as queixas de dores se torna preocupante para as questões de saúde, principalmente a longo prazo. 0 estudo de STEINMETZ, SEIDEL e NIEMIER (2008) reforça a importância de estudos como este. Os autores avaliaram um músico profissional de uma orquestra alemã com 44 anos de idade. As investigações mostraram problemas musculoesqueléticos como diminuição e protrusão dos discos intervertebrais, além dos problemas de estresse. Segundo os autores, o músico relatou

\begin{tabular}{|c|c|c|c|}
\hline \multicolumn{2}{|c|}{ Correlação } & ângulo visual & distância visua \\
\hline distância visual & $r\left(p^{*}\right)$ & $-0,74(0,036)$ & - \\
\hline altura da partitura & $r\left(p^{*}\right)$ & $-0,766(0,027)$ & $0,76(0,029)$ \\
\hline
\end{tabular}

* Pearson. Valores menores que 0,05 indicam associação estatisticamente significativa entre as variáveis analisadas 
queixas musculoesqueléticas na região do pescoço e ombro esquerdo, o que possibilitava apenas 30 minutos de prática diária com o instrumento, não permitindo a atuação profissional. Uma das considerações encontradas relacionadas às dores foi a flexão cervical durante 0 posicionamento do violino. Enquanto os autores indicaram angulações de $50^{\circ}$, o músico apresentou $80^{\circ}$ de flexão de cervical, valores estes superiores aos aqui encontrados.

No caso do presente estudo, a angulação da cervical foi de $49,86 \pm 5,71^{\circ}$. Mesmo que a angulação encontrada seja inferior a angulação recomendada por STEINMETZ, SEIDEL e NIEMIER (2008) há necessidade de se realizar pausas sistemáticas de descanso para diminuir a possibilidade de sobrecarga muscular e articular nessa região (IIDA, 2005). Outra indicação seria realizar avaliações mais aprofundadas com os ajustes da espaleira e da queixeira utilizadas para a prática instrumental, visto que estas podem influenciar a posição da cervical e dos membros superiores.

Acessórios que apresentem maiores possibilidades de regulagem vêm sendo apontados para o uso. Porém, mesmo que existam indicações de conformidade com as medidas antropométricas, na literatura nacional e internacional são poucos os estudos que voltem seus objetivos para estas relações. Além disso, não foram encontrados estudos que indiquem ao músico como fazer uso destes acessórios de forma a beneficiar as práticas instrumentais, diminuindo as tensões na região superior do corpo, principalmente na região cervical. 0 estudo de STEINMETZ, SEIDEL e NIEMIER (2008) pontuou as modificações necessárias para ajuste do ângulo da cervical. Ao identificar incompatibilidade entre queixeira e dimensões corporais do músico avaliado, por meio da angulação da cervical, foi sugerido o aumento da altura da queixeira com intuito de aproximar a mesma do queixo.
No caso da espaleira, BRANDFONBRENER (1989) faz recomendações a seu uso visando o aperfeiçoamento da posição da cabeça e pescoço e o alívio de tensão no ombro. 0 estudo de LEVY et al. (1992) veio a corroborar com estas indicações mostrando que a ativação muscular da região do ombro também foi modificada em função da utilização da espaleira.

\section{4 - Considerações finais}

Os resultados relacionados à altura da partitura musical, a distância visual, ao ângulo visual estão dentro das conformidades indicadas pela ergonomia. Apenas 0 ângulo da cervical, com valores de $49,86 \pm 5,71^{\circ}$, foi uma dimensão preocupante e fora dos padrões que indicam angulações de no máximo $30^{\circ}$ para atividades de trabalho.

A busca por estratégias que venham a contribuir para diminuição angular da cervical ainda é necessária, principalmente no que tange estudos mais aprofundados que vislumbrem a influência da queixeira e da espaleira na postura corporal e ângulo da cervical. Além disso, conforme o ritmo, novas exigências das obras musicais e troca de acessórios e/ou próprio instrumento, estas dimensões poderão ser modificadas. Mesmo assim, deverão estar dentro dos limites recomendados pela literatura, pois podem interferir nas condições visuais, físicas e de conforto dos músicos.

De forma geral, pode-se dizer que as dimensões estão dentro dos limites recomendados pela ergonomia, exceto o ângulo da cervical que deve ser investigado com maior profundidade em futuros estudos. No que tange a posição sentada, pode-se dizer que os músicos podem ser mais assistidos pela área da ergonomia de forma a aprender a utilizar o corpo corretamente durante as práticas.

\section{Referências}

AKESSON, I.; HANSSON, G. A.; BALOGH, I.; MORITZ, U.; SKERFVING, S. Quantifying work load in neck, shoulders and wrists in female dentists. International Archives of Occupational and Environmental Health, v. 69, p.461-474, 1997.

ARIENS, G. A. M.; BONGERS, P. M.; DOUWES, M.; MIEDEMA, M. C.; HOOGENDOORN, W. E.; VAN DER WAL, G.; BOUTER, L.; VAN MECHELEN, W. Are neck flexion, neck rotation, and sitting at work risk factors for neck pain? Results of a prospective cohort study. Occupational Environment Medicine, v. 58, n. 3, p.200-207, 2001.

BERKHOUT, A. L.; HENDRIKSSON-LARSÉN, K.; BONGERS, P. The effect of using a laptopstation compared to using a standard laptop PC on the cervical spine torque, perceived strain and productivity. Applied Ergonomics, v. 35, p.147-152, 2004.

BERQUE, P.; GRAY, H. The Influence of neck-shoulder pain on trapezius muscle activity among professional violin and viola players: an electromyographic study. Medical Problems of Performing Artists, v. 17, n. 2, p.68-75, 2002.

BLUM, J.; RITTER, M. D. Violinists and violists with masses under the left side angle of the jaw known as "fiddler's neck". Medical Problems of Performing Artists, v. 5, n. 1, p.155-160, 1990

BOISSÉ-RHEAULT, E.; BOUTHILLIER, P. La neuropathie du musicien - une corde bien tendue. Le Médecin Du Québec, Keith Health Care Communications Montréal. v. 35, n. 12, p.63-72, 2000.

BRANDFONBRENER, A. G. Interview with Cho-Liang (Jimmy) Lin. Medical Problems of Performing Artists, v, 4, n. 1, p.3-8, 1989. BRANDFONBRENER, A. G. Musculoskeletal problems of instrumental musicians. Hand Clinics, v. 19, n. 2, p.231-239, 2003.

BRASIL. Portaria SIT n. ${ }^{\circ}$ 13, de 21 de junho de 2007 (DOU 26/06/2007). Ergonomia. Disponível em: <http://www.mte.gov. br/legislacao/normas_regulamentaDORAS/nr_17.pdf>. Acesso em 30 nov. 2009. 
BRITO, P. M.; COSTA, C. K. L.; MEDEIROS NETO, C. F.; GUEDES, D. T.; MÁSCULO, F. S.; CARDIA, M. C. G.; SILVA, L. B. Análise da relação entre a postura de trabalho e a incidência de dores na coluna vertebral. In:ENCONTRO NACIONAL DE ENGENHARIA DE PRODUÇÃO, 23, 2003, Ouro Preto: Anais eletrônicos... Ouro Preto: Associação Brasileira de Engenharia de Produção, 2003.

CASTRO, P. C. G.; LOPES, J. A. F. Avaliação computadorizada por fotografia digital, como recurso de avaliação na Reeducação Postural Global. Acta Fisiatrica, v. 10, n. 2, p.83-88, 2003.

CHAFFIN, D. B. Localized muscle fatigue-definition and measurement. Journal of Occupational Medicine, v. 15, n. 4, p.346-354, 1973.

COSTA, C. P. Quando tocar dói: análise ergonômica da atividade de violistas de orquestra. Dissertação (Mestrado em Psicologia). 136f. Universidade de Brasília. Brasília, 2003.

COSTA, C. P. Contribuições da ergonomia à saúde do músico: considerações sobre a dimensão física do fazer musical. Música Hodie, v. 5, n. 2, p.53-63, 2005.

COSTA, C. P.; ABRAHÃO, J. I. Quando o tocar dói: um olhar ergonômico sobre o fazer musical. Performance Musical, v. 10, p.60-79, 2004.

DIMATOS, A. M. M. Condições de saúde e trabalho de violinistas da camerata florianópolis - um estudo de caso. 177f. Tese (Doutorado em Engenharia de Produção) - Universidade Federal de Santa Catarina.

DUARTE, M.; MALDONADO, E. P.; FREITAS, A. Z.; FERREIRA, E. A.; PRADO, J.; PASOUAL, A. P. et al. Software para Avaliação Postural. 2006 Disponível em: <http://sapo.incubadora.fapesp.br> Acesso em: 03 out 2005.

FJELLMAN-WIKLUND, A.; BRULIN, C.; SUNDELIN, G. Physical and psychosocial work-related risk factors associated with neckshoulder discomfort in male and female music teachers. Medical Problems of Performing Artists, v. 18, n. 1, p.33-41, 2003.

FLOYD, R. T.; THOMPSON, C, W. Manual de cinesiologia estrutural. São Paulo: Manole, 2002.

FONSECA, M. P. M. Principais desconfortos físico-posturais dos flautistas e suas implicações no estudo e na performance da flauta. Dissertação (Mestrado em Música). 106p. Universidade Federal de Minas Gerais. Belo Horizonte, 2005.

GLATZ, C. V. D. H.; POFFO, P.; PRZSIEZNY, W. L. Análise da incidência de dor e desconforto em músicos de Blumenau-SC. Revista FisioctTerapia, n. 51, p.18-19, 2006.

GRANDJEAN, E. Manual de Ergonomia. Adaptando o trabalho ao homem. Porto Alegre: Artes Médicas, 1998. 327p.

HANSSON, G. A.; MIKKELSEN, S. Kinematic evaluation of occupational work. Advanced Occupational Medicine and Rehabilitation, v. 1, p.57-69, 1997.

HAYNES, S.; WILLIAMS, K. Impact of seating posture on user comfort and typing performance for people with chronic low back pain. International Journal of Industrial Ergonomics, v. 38, p.35-46, 2008.

HUET, M.; MORAES, A. Medidas de pressão sob a pelve na postura sentada em pesquisas de ergonomia. Fisioterapia Brasil, v. 4, n. 6, p.438-444, 2003.

IIDA, Í. Ergonomia projeto e produção. São Paulo: Edgar Blucher, 2005.614p.

KAYIS, B.; HOANG, K. Static three-dimensional modelling of prolonged seated posture. Applied Ergonomics, v, 20, n. 3, p.255-262, 1999.

KINGMA, I.; VAN DIEËN, J. H. Static and dynamic postural loadings during computer work in females: Sitting on an office chair versus sitting on an exercise ball. Applied Ergonomics, v. 40, n. 2, p.199-205, 2008.

KÖENIG, I. Dort e violino: propostas para um tocar saudável. Trabalho de Conclusão de curso (Bacharelado em Música). 73p. Universidade do Estado de Santa Catarina. Florianópolis, 2007.

LEVY, C. E.; LEE, W. A.; BRANDFONBRENER, A. G.; PRESS, J.; LEVY, A. E. Electromyographic analysis of muscular activity in the upper extremity generated by supporting a violin with and without a shoulder rest. Medical Problems of Performing Artists, v. 7, n. 4, p.103-109, 1992.

MANDALOZZO, S. S. N.; COSTA, L. C. Breves considerações sobre ergonomia no ambiente de trabalho. Revista de Ciências Jurídicas, p.31-37, 2007.

MALINA, R. M. Tracking of physical activity and physical fitness across the lifespan. Research Quarterly for Exercise $\mathcal{C}$ Sport, v. 67, n. 3, p.48-57, 1996.

MARQUES, N. R.; HALLAL, C. Z.; GONÇALVES, M. Características biomecânicas, ergonômicas e clínicas da postura sentada: uma revisão. Fisioterapia e Pesquisa, v.17, n.3, p.270-6, 2010.

NORRIS, R. The musician's survival manual: a guide to preventing and treating injuries in instrumentalists. MMB Music, Inc, 1995. 134p.

OMB, Ordem dos Músicos do Brasil. 2009. Disponível em: <http://www.ombmg.org.br/ombmgv2/uploads/download/ leidecriacao.pdf>. Acesso em 03 ago. 2009.

PETRUS, A. M. F.; ECHTERNACHT, E. H. O. Dois violinistas e uma orquestra: diversidade operatória e desgaste músculoesquelético. Revista Brasileira de Saúde Ocupacional, v. 29, n. 109, p.31-36, 2004.

PHILIPSON, L.; SORBYE, R.; LARSSON, P.; KALADJEV, S. Muscular load levels in performing musicians as monitored by quantitative electromyography. Medical Problems of Performing Artists, v. 5, n. 2, p.79-82, 1990. 
SALVE, M. G. C.; BANKOFF, A. D. P. Análise da intervenção de um programa de atividade física nos hábitos de lazer. Revista Brasileira de Saúde ocupacional, v. 28, n, 105/106, p.73-82, 2004.

STEINMETZ, A.; SEIDEL, W.; NIEMIER, K. Shoulder pain and holding position of the violin. Medical Problems of Performing Artists, v. 2, n. 23, p.79-81, 2008.

STRAKER, L.; JONES, K. J.; MILLER, J. A comparison of the postures assumed when using laptop computers and desktop computers. Applied Ergonomics, v. 28, n. 4, p.263-268, 1997.

STRAKER, L.; MILLER, J.; MANGHARAM, J.; BATES, M.; POLLOCK, C. Performance effects of postural changes at a VDU work station. In:LUCZAK, H.; CAKIR, A. E.; CAKIR, G. Work With Display Units. Berlin: Institute for Arbeitswissenschaft, 1992.

TEIXEIRA, C. S.; KOTHE, F.; PEREIRA, É. P.; MORO, A. R. P.; MERINO, E. A. D. Trabalho e prática de exercícios físicos: o caso de músicos de orquestra. Lecturas Educación Física y Deportes, v. 13, n. 130, 2009. Disponível em: <http://www. efdeportes.com/efd130/exercicios-fisicos-o-caso-de-musicos-de-orquestra.htm> Acesso em 09 abr. 2009.

WATSON, A. H. D. What can studying musicians tell us about motor control of the hand? Journal of Anatomy, v. 208, n. 4, p.527-542, 2006.

WU, S. J. Occupational Risk Factors for Musculoskeletal Disorders in Musicians: A Systematic Review. Medical Problems of Performing Artists, v. 22, n. 2, p.43-51, 2007.

YI, L. C.; JARDIM, J. R.; INOUE, D. P.; PIGNATARI, S. S. N. The relationship between excursion of the diaphragm and curvatures of the spinal column in mouth breathing children. Journal of Pediatrics, v. 84, n. 2, p.171-177, 2008.

FLOYD, R. T.; THOMPSON, C, W. Manual de cinesiologia estrutural. São Paulo: Manole, 2002.

MARQUES, N. R.; HALLAL, C. Z.; GONÇALVES, M. Características biomecânicas, ergonômicas e clínicas da postura sentada: uma revisão. Fisioterapia e Pesquisa, v.17, n.3, p.270-6, 2010.

CALLAGHAN, J. P.; DUNK, N. M. Examination of the flexion relaxation phenomenon in erector spine muscles during short duration slumped sitting. Clinical Biomechanics, v. 17, n. 5, p.353-360, 2002.

O'SULLIVAN, P. B.; DANKAERTS, W.; BURNET, A. F.; FARRELL, G. T.; JEFFORD, E.; NAYLOR, C. S.; O'SULLIVAN, K. J. Effect of different upright sitting postures on spinal-pelvic curvature and trunk muscle activation in a pain-free population. Spine, v. 31, n. 19, p.707-712, 2006.

\section{Nota}

10 iliopsoas está situado na região ilíaca e consiste em três músculos diferentes: iliaco, psoas maior e menor. (1) Origem do iliopsoas: iliaco: superfície interna do ílio; psoas maior e menor: bordos inferiores dos processos transversos (L1-L5), corpos das últimas vértebras torácicas (T12), vértebras lombares (L1-L5), fibrocartilagens intervertebrais e base do sacro. (2) Inserção do iliopsoas: iliaco e psoas maior: trocânter menor do fêmur; psoas menor: linha pectinea e eminência iliopectínea. (3) Inervação do iliopsoas: nervo lombar e nervo femoral.

Clarissa Stefani Teixeira possui graduação em Educação Física pela Universidade Federal de Santa Maria (2004). Realizou especialização em Atividade Física, Desempenho Motor e Saúde na linha de pesquisa Biomecânica da Atividade Física pela Universidade Federal de Santa Maria (2005). É mestre em Distúrbios da Comunicação Humana pela Universidade Federal de Santa Maria (2006-2008). Atualmente tem seus estudos voltados para a saúde e qualidade de vida dos trabalhadores atuando principalmente na área de ergonomia, antropometria e biomecânica. É doutora em Engenharia de Produção da Universidade Federal de Santa Catarina na linha de pesquisa de Ergonomia.

Fausto Kothe possui graduação em Música (bacharelado em viola) pela Universidade Federal de Santa Maria (2004). Apresentou-se com as principais orquestras do estado do Rio Grande do Sul, Santa Catarina e Paraná. Atuou na docência e preparação de alunos para a graduação durante os anos de 2006-2009. Atualmente é mestrando em Música da Universidade Federal do Paraná na linha de pesquisa Educação Musical, Cognição e Filosofia.

Érico Felden Pereira é professor adjunto de Aprendizagem Motora e Desenvolvimento Humano do Centro de Ciências da Saúde e do Esporte (CEFID) da Universidade do Estado de Santa Catarina (UDESC). Possui Graduação, Mestrado e Doutorado em Educação Física e é Especialista em Atividade Física, Desempenho Motor e Saúde. Tem experiência nas áreas de Educação Física e Saúde atuando, especialmente, nos seguintes temas: aprendizagem e desenvolvimento motor, cronobiologia, ciclo vigília/sono, saúde do trabalhador, desigualdades em saúde e imagem corporal.

Eugenio Andrés Díaz Merino possui graduação em Desenho Industrial pela Universidade Federal do Rio de Janeiro (1993), mestrado em Engenharia de Produção pela Universidade Federal de Santa Catarina (1996) e doutorado em Engenharia de Produção pela Universidade Federal de Santa Catarina (2000). Atualmente é professor adjunto IV da Universidade Federal de Santa Catarina e coordena o Núcleo de Gestão de Design. Atualmente atua nos seguintes temas: ergonomia, gestão de design e usabilidade. Participa dos programas de Pós-Graduação em Design e Engenharia de Produção da UFSC. Faz parte do grupo de avaliadores do INEP/MEC e do Conselho Estadual de Educação de Santa Catarina na avaliação de cursos. 